
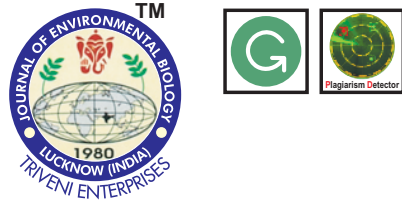

Journal of Environmental Biology

ISSN: 0254-8704 (Print) ISSN: 2394-0379 (Online) CODEN: JEBIDP

\title{
Behaviour of hexaconazole (Contaf \\ $5 \%$ EC) residues on two cultivars of \\ apple grown under temperate conditions of Kashmir, India
}

Authors Info

M. Bhat ${ }^{1 *}$, M. Mukhtar², A. Sherwani ${ }^{3}$ and A.A. Wani ${ }^{2}$

'Division of Plant Pathology, Sher-e-Kashmir University of Agricultural Sciences and Technology of Kashmir Srinagar-190 025, India

${ }^{2}$ Research Centre for Residue and Quality Analysis Sher-e-Kashmir University of Agricultural Sciences and Technology of Kashmir Srinagar-190 025, India

${ }^{3}$ Division of Entomology Sher-eKashmir University of Agricultural Sciences and Technology of Kashmir Srinagar-190 025, India

*Corresponding Author Email : mudasirpatho@gmail.com

Key words

Cultivar,

Dissipation,

Half-life,

Hexaconazole,

Residues

\section{Publication Info}

Paper received : 23.06.2016

Revised received: 02.02.2017

Re-revised received : 20.05.2017

Accepted : 26.05.2017

\section{Abstract}

Aim : Keeping in view the use of hexaconazole on apple in Kashmir, the dissipation behaviour at two dosages on two cultivars were studied to ascertain the residues at different time intervals, waiting period and theoretical maximum residue contribution (TMRC), so that its use may not pose any danger to the consumers and is acceptable in domestic and international markets.

Methodology : Hexaconazole (Contaf $5 \%$ EC) was applied at two dosages at 25 and $50 \mathrm{~g}$ a.i. ha ${ }^{-1}$ as single dose $\left(T_{1}\right)$ and double dose $\left(T_{2}\right)$ on Golden Delicious and Starkrimson cultivars of apple. Samples were processed by QuEChERS method for the estimation of hexaconazole residues in apple fruit and the final extract was analysed on gas chromatograph (GLC) coupled with an electron capture detector (ECD).

Results : The average initial deposits were found to be 2.60 and $4.01 \mu \mathrm{g} \mathrm{g}^{-1}$ on Golden Delicious and 2.43 and $3.98 \mu \mathrm{g} \mathrm{g}^{-1}$ on Starkrimson, at $\mathrm{T}_{1}$ and $\mathrm{T}_{2}$ doses, respectively. Residues of hexaconazole were well below $\mathrm{LOQ}$ of $0.008 \mu \mathrm{g} \mathrm{g}^{-1}$ at 30 day after treatment in $\mathrm{T}_{1}$ dose of both the cultivars. The half-lives of hexaconazole in Golden Delicious and Starkrimson were found to be 2.80, 5.41 and 2.73, 5.11 days in $T_{1}$ and $T_{2}$ doses, respectively.

Interpretation : The residues of hexaconazole dissipated below quantification level of $0.008 \mu \mathrm{g} \mathrm{g}^{-1}$ and waiting periods of 8.13 and 7.45 days are suggested for Golden Delicious and Starkrimson cultivars at recommended dose in Kashmir. Theoretical maximum residue contribution TMRC (the theoretical maximum amount of a pesticide in the daily diet of an average person) values were found to be 17.57 and $27.10 \mu \mathrm{g}$ person $^{-1}$ day $^{-1}$, far less than maximum permissible intake MPI, (which is a measure of the amount of a pesticide in food that can be ingested on a daily basis over a lifetime without an appreciable

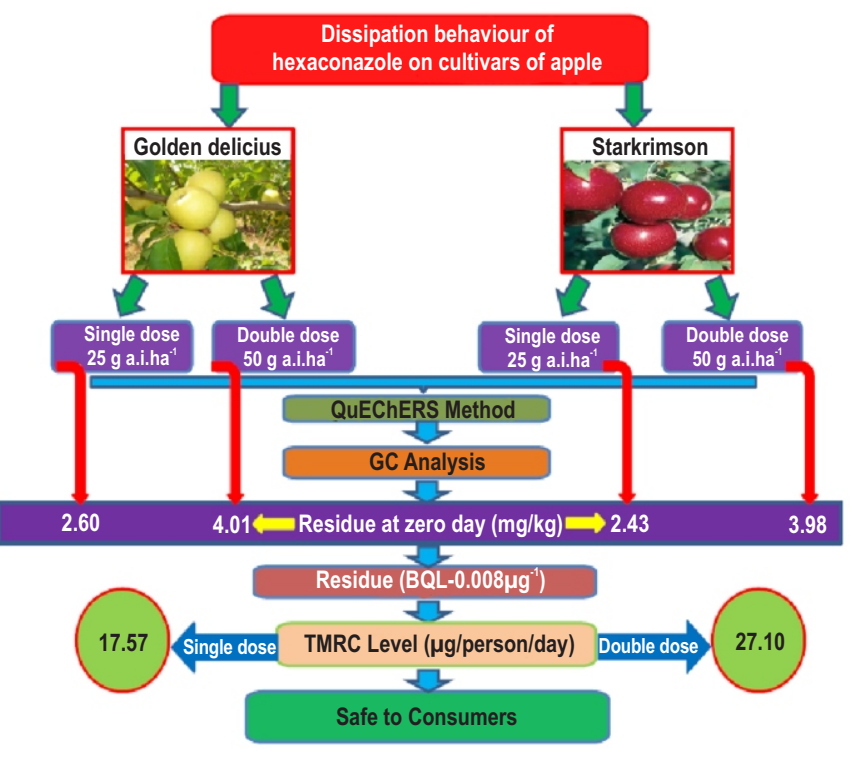
health risk) at 0 day in both the dosages indicating hexaconazole use on apple cannot put health of consumers at risk in Kashmir. 


\section{Introduction}

Pesticides provide an effective tool in mitigating the problems of diseases and insect pests on food crops. Use of pesticides on fruit crops provide an instant management of pests and are therefore, popular among the farmers because of their easy application, efficacy and good economic returns. Despite the fact that pesticides are used for controlling insect pests and diseases, along with their other beneficial effect leave trace amounts of residues on fruits and vegetables (Anwar et al. 2011). The Integrated Pest Management (IPM) strategies including biocontrol and pest resistant varieties are harnessed on limited scale and chemical control is still the most preferred technique to alleviate the pest problem in the country. Though broad-spectrum pesticides are excellent in their mode of action, high yield performance leading to high economic returns, they have serious drawbacks such as developing resistance against pesticides, pest resurrection and outbreak of secondary pests leading to the development of iatrogenic diseases (Gurusubramanian et al., 2008). Due to indiscriminate use of pesticides by the farmers, only a small portion of it reaches the target; rest reaches to environment including humans through food chain. Amongst food items, fresh fruits are the most important part of human diet as they are mostly consumed directly after picking as compared to vegetables and grains that are cooked, which in turn reduces and metabolizes the pesticide residues (Newsom et al., 2000). High chemical and biological stability coupled with higher degree of lipophilicity results in their accumulation in biological tissues and food commodities (Wania and Mackay, 1996) and environmental components (Seth et al., 1998).

Environmental dissipation of pesticides with time is an important phenomenon in nature that ameliorates the residue build-up. Degradation of pesticide residues, half-life and waiting period has been studied by various authors. Dissipation patterns of the fungicide difenoconazole ( $25 \% \mathrm{EC})$ in apples grown in Kashmir has been reported (Bhat et al., 2015). Half-life of flusilazole on apple was found to be 4.23-7.77 days when applied @ 1.25 and $1.875 \mathrm{gkg}^{-1}$ (Shuang et al., 2011). Waiting period of difenoconazole in apple was found to be 6 and 7 days at 66.7 and $100 \mathrm{mg} / \mathrm{kg}$ (Guo et al., 2010). Initial deposits of tetraconazole in mangoes were found to be 0.23 and $0.38 \mathrm{Mg} \mathrm{g}^{-1}$ and half-life values were 4 and 7.5 days at 50 and $100 \mathrm{~g}$ a.i.ha- (Samsul et al., 2011). Waiting period of another triazole fungicide propiconazole was found to be 3 and 7 days for grape and mango fruits (Soliman et al., 2017). Difenoconazole residues in apple and soil were found to be $0.002-0.052$ and $0.002-0.298 \mathrm{mg} \mathrm{kg}^{-1}$ while half-lives were in the range of 6.2-9.5 and 21.0-27.7 days at the application rate of $78 \mathrm{~g}$ a.i.ha ${ }^{-1}$ (He etal., 2016).

Pesticide residue problem happens to be serious when good agricultural practices are not followed due to which the consumers are easily exposed to high levels of pesticide residues. Keeping in view the safety of consumers, it is important to generate necessary information regarding pesticide residue levels in raw agricultural produce. Therefore, keeping in mind the risks involved in fungicide use and early harvest of Starkrimson cultivar of apple in Kashmir, the present work was carried out to study the dissipation behaviour of hexaconazole, safe waiting period, half-life and estimation of theoretical maximum residue contribution values in Golden Delicious and Starkrimson cultivar of apple under agro-climatic conditions of Kashmir.

\section{Materials and Methods}

Field trial : Field trial was carried out in the Horticultural Research Farm of Sher-e-Kashmir University of Agricultural Sciences and Technology of Kashmir, Shalimar, J\&K, India during the summer season (kharief) on Golden Delicious and Starkrimson cultivars of apple. The trial was laid in a randomised block design fashion. Each treatment was replicated thrice with each tree served as one replicate. Plant to plant and row to row distance was $3 \mathrm{~m}$. Hexaconazole (Contaf $5 \%$ EC) was sprayed one month prior to the harvest of apple at two levels $25 \mathrm{~g}$ a.i. ha ${ }^{-1}$ (recommended concentration of SKUAST-K, $\mathrm{T}_{1}$ ) and $50 \mathrm{~g}$ a.i. ha ${ }^{-1}$ (double the recommended, $T_{2}$ ). For studying dissipation of hexaconazole residues in apple, representative samples $1.5 \mathrm{~kg}(0.5 \mathrm{~kg}$ from each replicate) were collected at time 0 day (1 hour post application when the spray mixture had dried up) and $3,6,9,12$ days after application, and at the time of harvest that correspond to 30 day post treatment. Control trees were only sprayed with water.

Samples were placed in plastic bags and transported in iceboxes to laboratory for subsequent refrigeration at $-4^{\circ} \mathrm{C}$ till further processing. Minimum and maximum daily temperatures ranged from 11.0 to 18.0 and from 22.5 to $29.5^{\circ} \mathrm{C}$, respectively and average relative humidity and rainfall ranged between $52-88 \%$ and $0-1.9 \mathrm{~mm}$ during the experimental period (from spraying to last sampling).

Preparation of standard solution : The standard stock solution of hexaconazole $\left(1 \mathrm{mg} \mathrm{ml}^{-1}\right)$ was prepared in HPLC grade hexane: acetone in 1:1 ratio. The standard solutions required for constructing a calibration curve $\left(20,40,60,80\right.$ and $\left.100 \mathrm{ng} \mathrm{ml}^{-1}\right)$ were prepared from stock solution by serial dilution with hexane: acetone in 1:1 ratio. All the standard solutions were stored at $-2^{\circ} \mathrm{C}$ before use.

Chromatographic analysis : The final extracts were analysed on a Varian 450 (Walnut Creek, CA, USA) gas chromatograph (GLC) coupled with an electron capture detector (ECD Ni $\left.{ }^{63}\right)$. The capillary column used was CP SIL 8 CB $(30 \mathrm{~m} \times 0.25 \mu \mathrm{m}$ ID $\times 0.25$ $\mu \mathrm{m}$ film thickness of $5 \%$ diphenyl and $95 \%$ dimethylpolysiloxane), injector port temperature $280^{\circ} \mathrm{C}$ and detector temperature $300^{\circ} \mathrm{C}$. Column oven temperatures $60^{\circ} \mathrm{C}$ hold for 5 min then programmed at $10^{\circ} \mathrm{C} \mathrm{min}^{-1}$ up to $200^{\circ} \mathrm{C}$ (ramp I), hold for $1 \mathrm{~min}$, then $5^{\circ} \mathrm{C} \mathrm{min}^{-1}$ to $230^{\circ} \mathrm{C}$ (ramp II). Carrier gas nitrogen was used with flow of $1 \mathrm{ml} \mathrm{min}^{-1}$ through the column and detector make-up of $30 \mathrm{ml} \mathrm{min}{ }^{-1}$. Under these operating conditions, the retention time of hexaconazole was $16.45 \mathrm{~min}$. Total run time was $26 \mathrm{~min}$. Galaxy chromatography data system version 1.9.302.530 was used for the instrument control and data processing.

Processing of samples : Samples were processed by QuEChERS method as described by Lehotay et al. (2010) for the estimation of hexaconazole residues in apple fruit with slight modification. Samples of apple were chopped (with peel and pulp intact) on a cutting board 
and put in a blender and blended at $1000 \mathrm{rpm}$. Ten gram of homogenized apple sample was weighed in a $50 \mathrm{ml}$ centrifuge tube. Fifteen $\mathrm{ml}$ of $1.0 \%$ acidified acetonitrile with acetic acid was added to the tubes. The sample and MeCN were mixed together on a vortex mixer for $2 \mathrm{~min}$. For buffering of sample, $2 \mathrm{~g}$ of anhydrous $\mathrm{MgSO}_{4}, 0.5 \mathrm{~g}$ of $\mathrm{NaCl}, 0.5 \mathrm{~g}$ of trisodium citrate dihydrate $\left(\mathrm{C}_{6} \mathrm{H}_{9} \mathrm{Na}_{3} \mathrm{O}_{9}\right)$ and $0.25 \mathrm{~g}$ of disodium hydrogen citrate sesquihydrate $\left(\mathrm{C}_{6} \mathrm{H}_{8} \mathrm{Na}_{2} \mathrm{O}_{8}\right)$ were added. The screw caps of the tubes were tightly closed and shaken vigorously on a vortex mixer for $30 \mathrm{~s}$ and centrifuged on a Q-sep 3000 (Restek, USA) centrifuge for $5 \mathrm{~min}$ at $5000 \mathrm{rpm}$ for phase separation. For dispersive solid-phase extraction (dSPE), an aliquot of $10 \mathrm{ml}$ supernatant was taken and transferred in a $15 \mathrm{ml}$ centrifuge tube containing preweighed $1.0 \mathrm{~g} \mathrm{MgSO}_{4}, 150 \mathrm{mg}$ primary secondary amine (PSA) and $10 \mathrm{mg}$ graphitized carbon black (GCB). The tubes were shaken on vortex mixer for $1 \mathrm{~min}$. The tubes were again centrifuged for $5 \mathrm{~min}$ at $3000 \mathrm{rpm}$ to separate the solid material. About four $\mathrm{ml}$ of supernatant was taken in a flask of rotary vacuum evaporator (Heidolph instruments Schwabach GmbH Germany model: Hei-VAP Precision). The extract was evaporated to dryness and reconstituted with $1 \mathrm{ml}$ n-hexane. The extract was filtered through a PTFE syringe filter $(0.22 \mu \mathrm{m}$, Whatman, UK) and analysed on GCECD.

Data Analysis : The statistical analysis of data was carried out according to the Hoskins (1961) and TMRC was expressed as milligrams of pesticide $\mathrm{kg}^{-1}$ b. wt day ${ }^{-1}$.

\section{Results and Discussion}

Validation of method was accomplished in terms of recovery studies before analysis of control samples. The recovery study was performed at three different fortification levels $(0.07$, 0.10 and $0.20 \mathrm{ug} \mathrm{g}^{-1}$ ) and processed by the method described above and the average recovery ranged from 83.00 to $91.42 \%$. The recoveries for three levels were within 70 to $120 \%$ range (SANCO/12571/2014). The repeatability of method was expressed as percent relative standard deviation (RSD) and ranged from $0.14-1.76 \%$ suggesting that the extraction and clean up procedure could be regarded satisfactory for the routine analysis of hexaconazole on apple. The limit of detection (LOD) and limit of quantification (LOQ) for hexaconazole in apple fruit was found to be $0.004 \mathrm{ug} \mathrm{g}^{-1}$ and $0.008 \mathrm{ug} \mathrm{g}^{-1}$.

The average initial deposit of hexaconazole residues in Golden Delicious was 2.60 and $4.01 \mu \mathrm{g} \mathrm{g}{ }^{-1}$ for $T_{1}$ and $T_{2}$ doses. Residues on $3^{\text {rd }}$ day reached to 1.92 and $3.20 \mu \mathrm{g} \mathrm{g}-1$ which dissipated to 1.16 and $2.02 \mu \mathrm{g} \mathrm{g} \mathrm{g}^{-1}$ by $6^{\text {th }}$ day post treatment, with dissipation rate of $26.15,20.19$ and $55.38,49.62 \%$ in $T_{1}$ and $T_{2}$ doses, respectively. There was a steady decrease in the residues of hexaconazole and by the $12^{\text {th }}$ day the residues degraded to 0.098 and $0.81 \mu^{-1} g^{-1}$ with dissipation rate of 96.23 and $79.80 \%$ in $T_{1}$ and $T_{2}$ dosages, respectively. Residues reached below quantification limit of $0.008 \mu \mathrm{g} \mathrm{g}^{-1}$ at 30 th day post treatment in $\mathrm{T}_{1}$ dose, while $0.093 \mu \mathrm{g}$ $\mathrm{g}^{-1}$ were still detected in $\mathrm{T}_{2}$ dose with dissipation rate of $97.68 \%$ at same time interval. The half-life values $\left(T_{1 / 2}\right)$ of hexaconazole in Golden Delicious were found to be 2.80 and 5.41 days in $T_{1}$ and $T_{2}$ doses, respectively (Table 1). No detectable residues were found in the samples of control plots. Dissipation of hexaconazole residues versus time depicts first order kinetics i.e., degradation rate of hexaconazole residues was proportional to the initial deposit. These observations are in conformity with Mukhopadhyay et al. (2011) who reported half-life values of difenoconazole in the range 2.15-2.32 days for chilli fruit. Similar results were shown by Soliman et al. (2017) who reported waiting periods of 1.24 and 1.19 days for propiconazole in grape and mango fruits. Likewise, Sharma and Nath (1992) reported half- life values of 4-11.5 and 4.6-6.7 days for bitertanol when applied at 0.6 and $1.2 \mathrm{~kg} \mathrm{ha}^{-1}$ in apple.

Similarly in Starkrimson, the average initial deposit of hexaconazole residues was 2.43 and $3.98 \mu \mathrm{gg}^{-1}$ for $T_{1}$ and $T_{2}$ doses. Residues on $3^{\text {rd }}$ day reached to 1.17 and $3.01 \mu \mathrm{g} \mathrm{g}^{-1}$ with dissipation rate of 29.62 and $24.37 \%$ in $T_{1}$ and $T_{2}$ doses, respectively.

Table 1 : Hexaconazole residues, percentage dissipation at different time intervals, half-life $\left(T_{12}\right)$ and waiting period $\left(T_{\text {tol }}\right)$ in Golden Delicious variety of apple under temperate conditions of Kashmir

\begin{tabular}{|c|c|c|c|c|}
\hline \multirow{2}{*}{ Days } & Residues $^{*}(\mathrm{mg} / \mathrm{kg}) \pm \mathrm{SD}$ & \multicolumn{3}{|l|}{$\%$ Dissipation } \\
\hline & $\mathrm{T}_{1}$ & $\mathrm{~T}_{2}$ & $\mathrm{~T}_{1}$ & $\mathrm{~T}_{2}$ \\
\hline 0 & $2.60 \pm 0.002$ & $4.01 \pm 0.001$ & - & - \\
\hline 3 & $1.92 \pm 0.003$ & $3.20 \pm 0.008$ & 26.15 & 20.19 \\
\hline 6 & $1.16 \pm 0.003$ & $2.02 \pm 0.006$ & 55.38 & 49.62 \\
\hline 9 & $0.80 \pm 0.005$ & $1.21 \pm 0.003$ & 69.23 & 69.82 \\
\hline 12 & $0.098 \pm 0.002$ & $0.81 \pm 0.002$ & 96.23 & 79.80 \\
\hline 30 (At harvest) & $\mathrm{BQL}$ & $0.093 \pm 0.009$ & 100 & 97.68 \\
\hline $\begin{array}{l}\text { Regression } \\
\text { equation ( } Y=a-b x)\end{array}$ & $3.57-0.107 x$ & $3.61-0.055 x$ & & \\
\hline $\mathrm{T}_{1 / 2}$ & 2.80 & 5.41 & & \\
\hline$T_{\text {tol }}$ & 8.13 & 16.54 & & \\
\hline r & -0.908 & -1.00 & & \\
\hline
\end{tabular}

*Mean of three replicates; $T_{1 / 2}$ half- life; BQL Below Quantification Limit; $T_{\text {tol }}$ waiting period; SD standard deviation; $r$ correlation coefficient; $T_{1}$ single dose $\mathrm{T}_{2}$ double dose 
Table 2 : Hexaconazole residues, percentage dissipation at different time intervals, half-life $\left(T_{1 / 2}\right)$ and waiting period $\left(T_{\text {tol }}\right)$ in Starkrimson variety of apple under temperate conditions of Kashmir

\begin{tabular}{lllll}
\hline \multirow{2}{*}{ Days } & Residues ${ }^{*}\left(\mathrm{mg} \mathrm{kg}^{-1}\right) \pm \mathrm{SD}$ & \% Dissipation & \\
\cline { 2 - 5 } & $\mathrm{T}_{1}$ & $\mathrm{~T}_{2}$ & $\mathrm{~T}_{1}$ & $\mathrm{~T}_{2}$ \\
\hline 0 & $2.43 \pm 0.002$ & $3.98 \pm 0.002$ & - & - \\
3 & $1.17 \pm 0.008$ & $3.01 \pm 0.006$ & 29.62 & 24.37 \\
6 & $0.99 \pm 0.016$ & $2.08 \pm 0.005$ & 59.25 & 47.73 \\
9 & $0.53 \pm 0.002$ & $1.90 \pm 0.012$ & 78.18 & 52.26 \\
12 & $0.094 \pm 0.001$ & $1.12 \pm 0.002$ & 96.13 & 71.85 \\
30 (At harvest) & $\mathrm{BQL}$ & $0.072 \pm 0.009$ & 100 & 98.19 \\
Regression & & & & \\
equation (Y= a-bx) & $3.52-0.110 \mathrm{x}$ & $3.68-0.058 \mathrm{x}$ & \\
T1/2 & 2.73 & 5.11 & & \\
Ttol & 7.45 & 16.89 & & \\
$\mathrm{r}$ & -0.931 & -0.985 & & \\
\hline
\end{tabular}

*Mean of three replicates $; T_{1 / 2}$ half- life; BQL Below Quantification Limit; $T_{\text {tol }}$ waiting period; SD standard deviation; $r$ correlation coefficient; $T_{1}$ single dose $T_{2}$ double dose

Table 3 : Theoretical maximum residue contribution (TMRC) of hexaconazole in Golden Delicious and Starkrimson cultivars of apple under temperate conditions of Kashmir

\begin{tabular}{llllll}
\hline Cultivar & $\mathrm{T}_{1}$ & & & $\mathrm{~T}_{2}$ & \\
\hline & $\begin{array}{l}\text { Time after } \\
\text { application (days) }\end{array}$ & $\begin{array}{l}\text { Maximum } \\
\text { residue }\left(\mu \mathrm{g} \mathrm{g}^{-1}\right)\end{array}$ & $\begin{array}{l}\text { TMRC }(\mu \mathrm{g} \\
\left.\text { person }^{-1} \mathrm{day}^{-1}\right)\end{array}$ & $\begin{array}{l}\text { Maximum } \\
\text { residue }\left(\mu \mathrm{g} \mathrm{g}^{-1}\right)\end{array}$ & $\begin{array}{l}\text { TMRC }(\mu \mathrm{g} \\
\left.\text { person }^{-1} \text { day }^{-1}\right)\end{array}$ \\
\hline Golden & 0 & 2.60 & 17.57 & 4.01 & 27.10 \\
delicious & 3 & 1.92 & 12.97 & 3.20 & 21.63 \\
& 6 & 1.16 & 7.84 & 2.02 & 13.65 \\
& 9 & 0.80 & 5.40 & 1.21 & 8.17 \\
& 12 & 0.098 & 0.66 & 0.81 & 5.47 \\
& 30 & $\mathrm{BQL}$ & - & 0.093 & 0.62 \\
& 0 & 2.43 & 16.42 & 3.98 & 26.90 \\
& 3 & 1.17 & 7.90 & 3.01 & 20.34 \\
& 6 & 0.99 & 6.69 & 2.08 & 14.06 \\
& 9 & 0.53 & 3.58 & 1.90 & 12.84 \\
& 12 & 0.094 & 0.63 & 1.12 & 7.57 \\
\end{tabular}

Thereafter, a steep decline was observed in hexaconazole residue content and by $6^{\text {th }}$ day the residues degraded to 0.99 and $2.08 \mu \mathrm{g} \mathrm{g}^{-1}$ which further fell to 0.53 and $1.90 \mu \mathrm{g} \mathrm{g}^{-1}$ on $9^{\text {th }}$ day post treatment, with corresponding dissipation rate of $59.25,47.73$ and 78.18 , $52.26 \%$ in $T_{1}$ and $T_{2}$ doses respectively. On 12th day, the residues dissipated to 0.094 and $1.12 \mu^{-1} g^{-1}$ with dissipation rate of 96.13 and $71.85 \%$ in $\mathrm{T}_{1}$ and $\mathrm{T} 2$ doses, respectively. Residues reached below quantification limit of $0.008 \mu \mathrm{g} \mathrm{g}^{-1}$ at $30^{\text {th }}$ day post treatment in $\mathrm{T}_{1}$ dose, while $0.072 \mu \mathrm{gg}^{-1}$ was still detected in $\mathrm{T}_{2}$ dose with dissipation rate of $98.19 \%$ at same time interval. The half-life values $\left(T_{12}\right)$ of hexaconazole in Starkrimson were found to be 2.73 and 5.11 days in $T_{1}$ and $T_{2}$ doses. No detectable residues were found in the samples of control plots. Dissipation of hexaconazole residues versus time depicted first order kinetics i.e. degradation rate of hexaconazole residues were proportional to the initial deposit. Similar kinetics had been observed in mango by Samsul et al. (2011) who reported initial deposit of $0.23 \mu \mathrm{g} \mathrm{g}^{-1}$ at zero days and amount of residue was reduced to $0.02{\mu g g ~ g^{-1}}^{-1}$ after fifteen days.

Degradation of hexaconazole residues in the two cultivars of apple indicated a fairly similar trend with Starkrimson cultivar displaying a slightly slow dissipation rate as compared to Golden Delicious cultivar in $\mathrm{T}_{2}$ (double the recommended) dose. Juan et al. (2011) observed half-life values of 7.1 to 8.8 days in apple and reported a pre harvest interval of 21 days when hexaconazole was applied at recommended dosage on apple, whereas $\mathrm{He}$ et al. (2016) reported the half-life of difenoconazole as 6.2-9.5 and 21.0-27.7 days in apple and soil. Bhat et al. (2015) also reported the half-life and waiting period of $6.09,5.34$ and $13.06,10.72$ days of difenoconazole at recommended dose on 
Golden delicious and Starkrimson cultivars of apple in Kashmir. The slower rate of dissipation in case of higher dose of hexaconazole may be due to lower temperature and humidity prevalent in Kashmir as both these factors favour the rate of degradation (Maria and Lenart, 2007). The Japan food chemical research foundation has prescribed maximum residue limit (MRL) of $0.5 \mu \mathrm{g} \mathrm{g}^{-1}$ for hexaconazole on apple (Anonymous, 2015). It was found that the residues of hexaconazole @ 25 and $50 \mathrm{~g}$ a.i ha ${ }^{-1}$ were lower than the MRL value at 12 and 30 days after spray in $T_{1}$ and $T_{2}$ dose of both the cultivars. Therefore, the waiting periods (Ttol) of 8.13 for $T_{1}$ and 16.54 days for $T_{2}$ in case of Golden Delicious and 7.45 for $T_{1}$ and 16.89 days for $T_{2}$ in case of Starkrimson (Table 1 and 2) are considered safe for the consumption of hexaconazole treated apples under temperate conditions of Kashmir.

Safety of public health is of growing concern as consumption of pesticide laden food has direct effect on human health. Therefore, the hazards to the consumers with the use of hexaconazole were assessed by comparing maximum permissible intake (MPI) with dietary exposure. The acceptable daily intake (ADI) of hexaconazole is $0.005 \mathrm{mg} \mathrm{kg}^{-1}$ b.wt day ${ }^{-1}$ (Anonymous, 2014). The MPI was calculated by multiplying the ADI with the body weight of an average adult $(60 \mathrm{~kg})$. The obtained MPI of hexaconazole was $300 \mu$ person $^{-1} \mathrm{day}^{-1}$. On the basis of average per capita daily consumption of $6.76 \mathrm{~g}$ of apple in India (Anonymous, 2012), theoretical maximum residue contribution (TMRC) at 0 day was found to be 17.57 and 27.10 $\mu \mathrm{g}$ person ${ }^{-1}$ day $^{-1}$ for $T_{1}$ and $T_{2}$ dose in Golden Delicious, whereas in case of Starkrimson, at 0 day the TMRC values were found to be 16.42 and $26.90 \mu$ p person $^{-1}$ day $^{-1}$ for $T_{1}$ and $T_{2}$ dose (Table 3). The TMRC values were far less than MPI at both the doses; therefore the hazards caused due to intake of hexaconazole treated apples in Kashmir are negligible even if double the recommended dose is applied.

The waiting periods of 13.81 and 14.65 days were worked out for Starkrimson and Golden Delicious at single dose. Therefore, hexaconazole treated apple could be considered safe for human consumption in Kashmir after observing waiting periods.

\section{Acknowledgements}

The authors thank the Head, Division of Plant Pathology and Director Research SKUAST-K for financial assistance received during the study. Our special thanks to Dr. Ali Anwar, Division of Plant Pathology for his constant encouragement, valuable suggestions and generous help during preparation of this manuscript.

\section{References}

Anonymous : Acceptable Daily Intakes for Agricultural and Veterinary Chemicals: Current as of 31 December 2014. The Department of Health, Australian Government. http://www.health.gov.au/i nternet/main/ publishing.nsf/ content/ocs-adi-list.htm (2014).

Anonymous: Household consumption of various goods and services in
India. National sample survey office. Ministry of statistics and programme implementation, Government of India. NSS report No: $541(2012)$

Anonymous: Revision of MRLs of agricultural chemicals, feed additives and veterinary drugs (September 18, 2015). The Japan Food Chemical Research Foundation http://www.ffcr.or.jp/zaidan/ (2015).

Anwar, T., I. Ahmad And S. Tahir: Determination of pesticide residues in fruits of Nawabshah district, Sindh, Pakistan. Pak. J. Bot., 43, 1133-1139 (2011).

Bhat, M., A.A. Wani, M. Mukhtar, A. Sherwani, A.H. Bhat and A. Showkat: Dissipation patterns of the fungicide difenaconazole $(25 \% \mathrm{EC})$ in apples grown in Kashmir, India. Environ. Monit. Assess., 187, 398$402(2015)$.

Guo, C., J.Z. Li and B.Y. Guo: Determination and safety evaluation of difenoconazole residues in apples and soils. Bull. Environ. Contam. Toxicol., 85, 427-431(2010).

Gurusubramanian, G., A. Rahman, M. Sarmah, S. Ray and S. Bora: Pesticide usage pattern in tea ecosystem, their retrospects and alternative measures. J. Environ. Biol., 29, 813-826 (2008).

$\mathrm{He}$, M., C. Jia, E. Zhao, C. Li, P. Yu, J. Jing and Y. Zheng: Concentrations and dissipation of difenoconazole and fluxapyroxad residues in apples and soil, determined by ultrahigh-performance liquid chromatography electrospray ionization tandem mass spectrometry. Environ. Sci. Pollut. Res., 23, 5618-5626.(2016)

Hoskin, W.M.: Mathematical treatment of the rate of loss of pesticide residues. FAO Plant Prot. Bull., 9, 163-168 (1961).

Hwang, J.I. and J.E. Kim: Residue patterns of fungicides, flusilazole and myclobutanil in apples. Curr. Res. Agr. Lif. Sci., 31, 272-279 (2013).

Juan, R.L., Y.U. Lei, S. Chun, Y.U. Xing and L.I. Liang: Residue and application safety assessment of hexaconazole in apple and soil. J.Agrochem., 10, (2011)

Lehotay, S.J., K.A. Son, H. Kwon, U. Koesukwiwat, W. Fu, K. Mastovskak, E. Hoh and N. Leepipatpiboon: Comparison of QuEChERS sample preparation methods for the analysis of pesticide residues in fruits and vegetables. J. Chromatog. A., $1217,2548-2560$ (2010).

Maria, P.C. and T. Lennart: Effect of biobed composition, moisture and temperature on the degradation of pesticides. J. Agr. Food Chem., 55, 5725-5733 (2007).

Mukhopadhyay, S., S. Das, A. Bhattacharyya and S. Pal: Dissipation study of difenoconazole in/on chili fruit and soil in India. Bull. Environ. Contam. Toxicol., 87, 54-57 (2011).

Newsome, W.H., J. Doucet, D. Davies and W.F. Sun: Pesticide residues in the Canadian Market Basket Survey 1992 to 1996. Food Addit. Contam., 17, 847-854 (2000).

Samsul, A., R.K. Kole and A. Bhattacharyya: Residual fate of the fungicide tetraconazole ( $4 \% \mathrm{EW})$ in mango. Bull. Environ. Contam. Toxicol., 87, 444-447 (2011).

Seth, P.K., R.B. Raizada and R. Kumar: Agricultural chemicals use and residue management in India, ACIAR, Proceedings No. p. 85 (1998). Sharma, I.D. and A. Nath: Determination of bitertanol residues in apple applied for the control of apple scab (Venturia inaequalis L.). PestRes J., 4, 155-158 (1992).

Shuang, Y., Q. Dong Mei, W. Qiong, G. Xing Li, H. Li Jun and J. Shu Ren: Residue and dissipation dynamics of flusilazole in apple and soil. Bull. Environ. Contam. Toxicol., 86, 319-322 (2011).

Soliman, A.S., M. A. H. Rania, I. N. Nasr, M. S. Abbas, H. A. Mahmoud and W. Jiang: Behavior of thiophanate methyl and propiconazole in grape and mango fruits under the Egyptian Field Conditions. Bull. Environ. Contam. Toxicol., 98, 720-725 (2017).

Wania, F. and D. Mackay: Tracking the distribution of persistent organic pollutants. Environ. Sci. Technol., 30, 390A-396A(1996). 